\title{
Diffuse illuminance availability on horizontal and vertical surfaces at Madrid, Spain
}

\author{
Pilar Oteiza ${ }^{\mathrm{a}}$, Ana Pérez-Burgos ${ }^{\mathrm{b}, *}$ \\ ${ }^{a}$ Department of Physics and Applied Installations to Buildings, Environment and Town Planning, High Technical School of Architecture, Polytechnic University of Madrid, \\ 28080 Madrid, Spain \\ ${ }^{\mathrm{b}}$ Department of Applied Physics, University of Valiadolid, 47005 Valladolid, Spain
}

\section{A R T I C L E I N F O}

Article history:

Received 10 November 2011

Received in revised form 24 May 2012

Accepted 24 May 2012

Available online 26 September 2012

Keywords:

Illuminance

Irradiance

Diffuse radiation

Daylighting

Luminous efficacy

\begin{abstract}
A B S T R A C T
The overall objective of this work is to provide diffuse illuminance availability at Madrid (Spain) through a statistical analysis of illuminance values corresponding to a long-term data series. The illuminance values are obtained from irradiance measurements by means of different empirical models for luminous efficacy. The values of diffuse illuminance on a horizontal and on vertical surfaces facing the four cardinal points are estimated and the different aspects related to daylight availability in an area with specific climatic conditions are analyzed. The experimental data consist of global and diffuse irradiance measurements on a horizontal surface provided by the National Meteorological Agency in Spain (AEMET) for Madrid. These data consist of hourly values measured in the period of 1980-2005. The statistical results derived correspond to a daylight typical year for the five surfaces considered. This information will be useful to building experts to estimate natural illumination availability when daylighting techniques are applied in building design with the main aim of electric energy savings.
\end{abstract}

\section{Introduction}

Daylight availability is the amount of daylight available at a specific location, time, date and sky condition. The knowledge of daylight availability for each geographical area contributes to a rational use of electric energy in buildings and consequently to energy savings in the area. Moreover, a better visual comfort inside buildings is obtained if daylighting techniques are applied in buildings. For an optimum assessment of daylight availability, longterm series of illuminance data are required. Only by analyzing such time series, it is possible to get a good understanding of the behavior of outdoor illuminance in a geographic region.

The International Daylight Measurement Project (IDMP) was launched in 1991 by the International Commission on Illumination (CIE). As a result, illuminance data series started to be collected on an international scale. However, the number of illuminance measurement stations is still scarce and the now available time series hardly exceed a 5-year period [1]. Due to illuminance data bases do not exist at most places of the world, illuminance data, when needed, are obtained from irradiance data, being this magnitude more commonly measured. Modeling illuminance from irradiance has been the aim of many researchers during the past years. A brief revision of some of these models is made in López and Gueymard [2] and Pérez-Burgos et al. [3].

\footnotetext{
* Corresponding author. Tel.: +34 645891222.

E-mail addresses: mariapilar.oteiza@upm.es (P. Oteiza), anapb@uva.es (A. PérezBurgos).
}

Most of the authors deal with luminous efficacy instead of illuminance. The luminous efficacy is defined as the ratio between illuminance and irradiance. In the case of dealing with diffuse components and horizontal surfaces, it is defined as:

$K_{d h}=\frac{L_{d h}}{E_{d h}}$

where $L_{d h}$ is the horizontal diffuse illuminance and $E_{d h}$, the horizontal diffuse irradiance. Similarly, the vertical luminous efficacy is defined in the same way. The luminous efficacy depends on the solar geometry and the sky conditions.

In literature, it is possible to find several studies proposing luminous efficacy models for the several radiation components. Specifically, at Madrid, Oteiza and Soler [4] and Robledo and Soler $[5,6]$ have proposed models for the luminous efficacy of diffuse solar radiation for horizontal and inclined surfaces. These authors have carried out extensive analysis of long-term illumination measurements which are often referred in literature [7-9]. The formulation of these models is based on empirical relationships with solar elevation and brightness index. Cucumo et al. [10] applied the Robledo and Soler model for inclined surfaces to Arcavacata di Rende (Italy) by using local empirical coefficients calculated for their location. They conclude that, when all sky types are analyzed together, low errors are obtained, similarly to other models analyzed. In addition, a version of the model for clear skies and global illuminances [11] was validated by Pérez-Burgos et al. [3] with measured data from Valladolid (Spain), located $200 \mathrm{~km}$ from Madrid. 
Numerous empirical models have been developed in other geographical regions to calculate the several components of illuminance [12-14]. These models have been extensively analyzed in numerous papers and significant comparative studies have been carried out [15-20]. A comprehensive compilation of models concerning daylighting can be found in Muneer [21].

The model of Perez [14] is perhaps the most widely used in literature; it has been validated in numerous works and is usually considered to be fairly accurate [22]. This model has been taken as reference in the present work.

Regarding the existing data base of illuminance measurements, there is a need for more long-term illuminance measurements worldwide [23]. Nevertheless, some studies can be cited based on illumination measurements for several years. So, Ne'eman et al. [24] reported a database of monthly mean hourly values of global and diffuse horizontal illuminance for Israel and the nearby region, Bartzokas et al. [25,26] compare sky luminances for different European climates, Markou et al. [1] studied the variation of illuminance levels for different seasons in Athens, Pérez-Burgos et al. [3,27] analyzed measurements of global horizontal and vertical illuminances at Valladolid, Spain, to evaluate their daily and annual variation in the area. Soler et al. [28] reported monthly mean hourly values of diffuse illuminance for Madrid in the period 19921998.

In the present work, a study of daylight availability for Madrid relying on long term data series has been carried out. It is expected that other geographical areas with similar climate characteristics can exploit these results $[28,26,25]$. This study is focused on the diffuse component of illuminance. Values of illuminance have been obtained from those of irradiance through luminous efficacy models; specifically, models by Robledo and Soler and by Perez have been applied as described in the following sections.

\section{Experimental data}

Experimental measurements of global and diffuse irradiances on horizontal surface were provided by the National Meteorological Agency (AEMET). The radiometric station is sited at Madrid $\left(40^{\circ} 27^{\prime} \mathrm{N}, 3^{\circ} 43^{\prime} \mathrm{W}\right)$, Spain. The data correspond to the period from 1980 to 2005, that is, a period of 26 years has been included in the analysis. The data are mean hourly values. For each day, data from 5:00 h to 20:00 h were available, so that, the irradiance value for a specific hour of the day corresponds to the average over the hour before. Time is expressed in True Solar Time (TST).

Madrid is affected by the Mediterranean continental climate as the majority of inner areas in Spain. This type of climate is characterized by wide diurnal and seasonal variations in temperature and by low, irregular rainfall. Continental winters are cold, and summers are warm and cloudless.

Due to the long-term series analyzed, a large amount of data was collected and treated as described next. In this way, the statistical results obtained in this work represent a typical behavior of irradiance and illuminance for the detailed climatic conditions.

\section{Estimation of diffuse illuminance on horizontal surface}

The empirical model of Robledo and Soler [5] is used to calculate diffuse illuminance on horizontal plane. The experimental data used by these authors to develop their model consisted of mean hourly values of diffuse irradiances and illuminances on horizontal surface measured at the High School of Architecture (ETSAM) at Madrid during the period from June 1994 to November 1995. After performing statistical assessments by considering different possible input variables, they proposed a general and simplified model to estimate the luminous efficacy which uses the brightness index $\Delta$ as the only input parameter:

$K_{d h}=91.07 \Delta^{-0.254}$

where the brightness index $\Delta$ is defined as:

$\Delta=\frac{E_{d h}}{E_{0} \sin \alpha}$

with $E_{0}$ the extraterrestrial irradiance (a value of $1367 \mathrm{~W} / \mathrm{m}^{2}$ was taken) and $\alpha$ the solar altitude. The expression (2) is valid for all sky types and its empirical coefficients are calculated for Madrid.

Diffuse horizontal illuminance is obtained from irradiance throughout:

$L_{d h}=K_{d h} E_{d h}$

In this work, the value of $K_{d h}$ is calculated by expression (2) and $E_{d h}$ is the experimental diffuse irradiance provided by AEMET. Values of diffuse illuminance for each hour have been calculated for the period 1980-2005, but, before this, an assessment of them was performed as follows. In Soler et al. [28], a brief study of the diffuse illuminance values obtained on horizontal surface at the measuring site of ETSAM for the period 1992-1998 is made. The experimental monthly averages hourly values of diffuse illuminance are given in the paper. These measurements have been used to validate the estimated illuminance values. The ETSAM radiometric station is located $2 \mathrm{~km}$ from the AEMET station at Madrid.

The estimated monthly mean hourly illuminance values are compared with measured values in Fig. 1 for the period 19921998. In this figure, representative graphs corresponding to June and December are shown. These graphs represent the variation of illuminance for two months with maximum and minimum illumination, respectively. Similar comparative results are obtained for other months, but not shown. Relative errors between estimated and measured values have been calculated. The averaged absolute relative error is $4.5 \%$ for June and $6.7 \%$ for December. For other months, these errors vary from $3.6 \%$ to $8.4 \%$. By considering all months, an averaged relative error of $5.3 \%$ is obtained. The adjustment between both types of curves proves the high accuracy of the model for the location of interest.

Based on this assessment, values of diffuse illuminance were estimated for the whole period 1980-2005. The monthly average hourly values are graphically shown in Fig. 2 as an iso-lux diagram type, firstly introduced by Kambezidis et al. [29]. Of course, at noon, diffuse illuminace is maximum, ranging from 15.99 klux in December to 34.28 klux in May.

For daylighting designs, cumulative frequency distributions of daylight availability can be used for determining the necessary use of artificial lighting, since they indicate the percentage of frequency in which a given illuminance value is exceeded. In Fig. 3, the cumulative frequencies of diffuse illuminance on an annual and monthly basis for horizontal surface are shown. From this figure, it can be seen how the differences between curves corresponding to different months of the year are significant. This feature coincides with findings by Chirarattananon et al. [30]. Following these authors, the differences between the availability of illuminance for different months of a year are small for Bangkok but they are important for United Kingdom and other locations far from the equator. Darker line, obtained by considering the whole data set, shows an average behavior between lines for each month. Months with more or less illumination can be observed from the graph. Maximum and minimum daylight availability is found in May and December, respectively. For these months, maximum values about 54 klux and 26 klux are, respectively, obtained. 

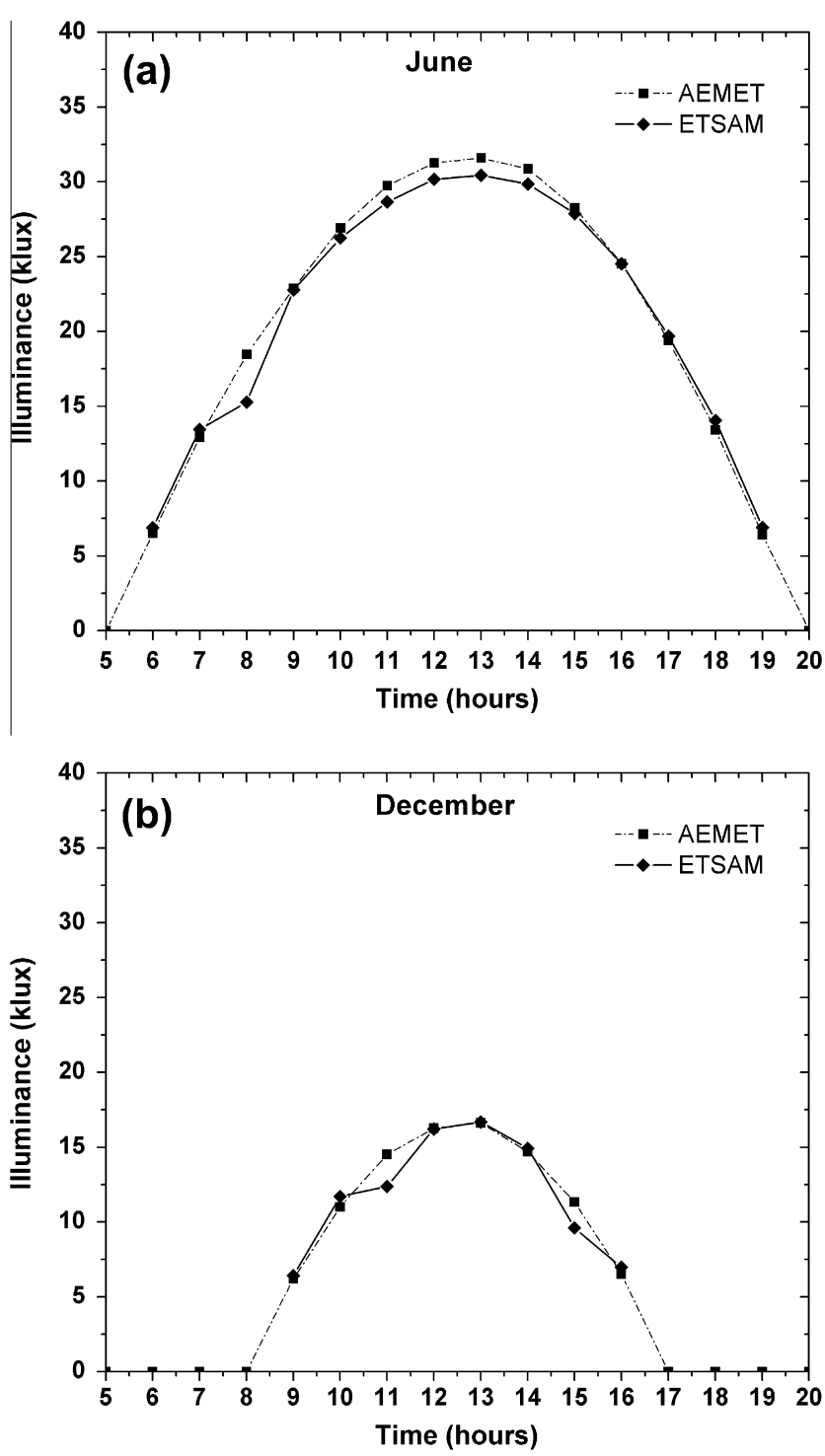

Fig. 1. Mean hourly values of diffuse illuminance on horizontal surface estimated from irradiance data of AEMET and measured at ETSAM for the period 1992-1998.

\section{Horizontal irradiance and illuminance and sky conditions at Madrid}

A study of the sky conditions at Madrid has been made with the aim of establishing the influence of the presence of clouds in the levels of irradiance and illuminance. To carry out this analysis, a classification of the sky types occurred at Madrid for the experimental period analyzed was made. Specifically, data were classified in eight cloudiness categories following the sky clearness parameter $\varepsilon$ of Perez et al. [14]:

$$
\begin{aligned}
\varepsilon= & \left\{\left[\left(E_{d h}+E_{b n}\right) / E_{d h}\right]+5.535 \times 10^{-6} Z^{3}\right\} /(1+5.535 \\
& \left.\times 10^{-6} Z^{3}\right)
\end{aligned}
$$

where $E_{d h}$ is the horizontal diffuse irradiance, $E_{b n}$ the direct normal irradiance and $\mathrm{Z}$ the solar zenith angle in degrees.

Depending on the value of $\varepsilon$, the sky is classified from category 1 (overcast) to category 8 (totally clear). In Fig. 4 , the number of data for each category is shown in order to see the occurrence of a specific sky condition in the studied geographical zone. Sky category 6 is the most abundant at Madrid (21.3\%). Totally clear skies have a

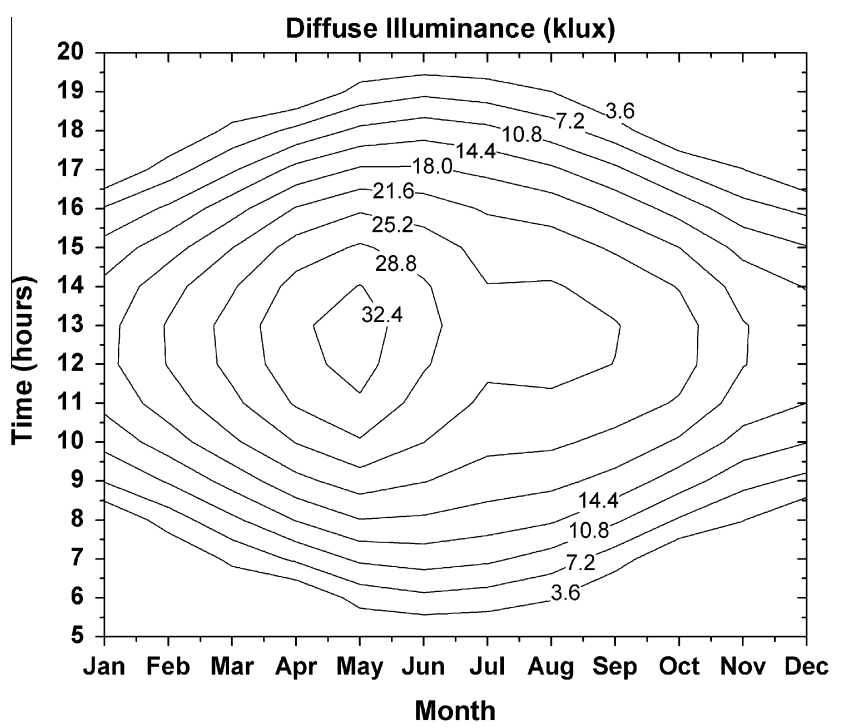

Fig. 2. Iso-lux lines diagram of diffuse illuminance on horizontal surface for Madrid for the period $1980-2005$.

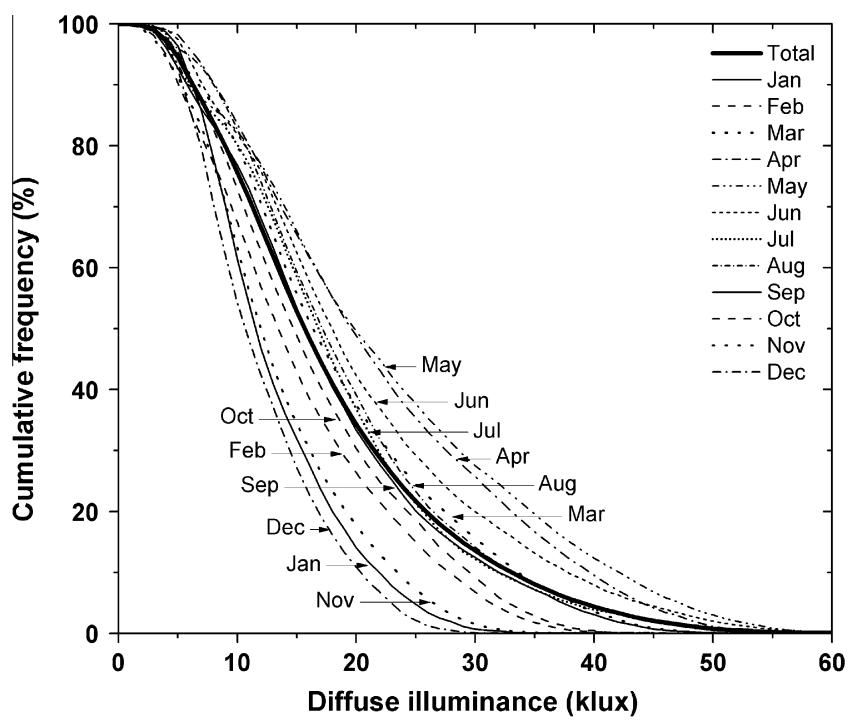

Fig. 3. Cumulative frequency distribution of diffuse illuminance on horizontal surface for Madrid for the period 1980-2005.

relatively high frequency representing $17.5 \%$ of the cases. If categories 6,7 and 8 are considered together representing the tendency to clear skies at Madrid, they sum up to 53.4\%. It is understood that these data represent the sky conditions at Madrid within the selected 26 years.

Fig. 5 shows mean values of global and diffuse irradiance for each sky category. It is seen that while global irradiance increases with decreasing cloudiness, the diffuse component grows and then decreases when cloudiness decreases. The maximum diffuse irradiance, a value of about $184 \mathrm{~W} / \mathrm{m}^{2}$, is obtained for partially cloudy skies (categories 3 and 4). The values of global irradiance for the extremes categories 1 and 8 are $146 \mathrm{~W} / \mathrm{m}^{2}$ and $675 \mathrm{~W} / \mathrm{m}^{2}$, respectively, and the values of diffuse irradiance are for these categories $142 \mathrm{~W} / \mathrm{m}^{2}$ and $80 \mathrm{~W} / \mathrm{m}^{2}$, that is, lower for clear skies than for overcast.

In Fig. 6, diffuse illuminace for each sky category is shown; as for irradiance, the highest value corresponds to partially cloudy skies (categories 3 and 4 ) followed by the overcast skies. The low- 


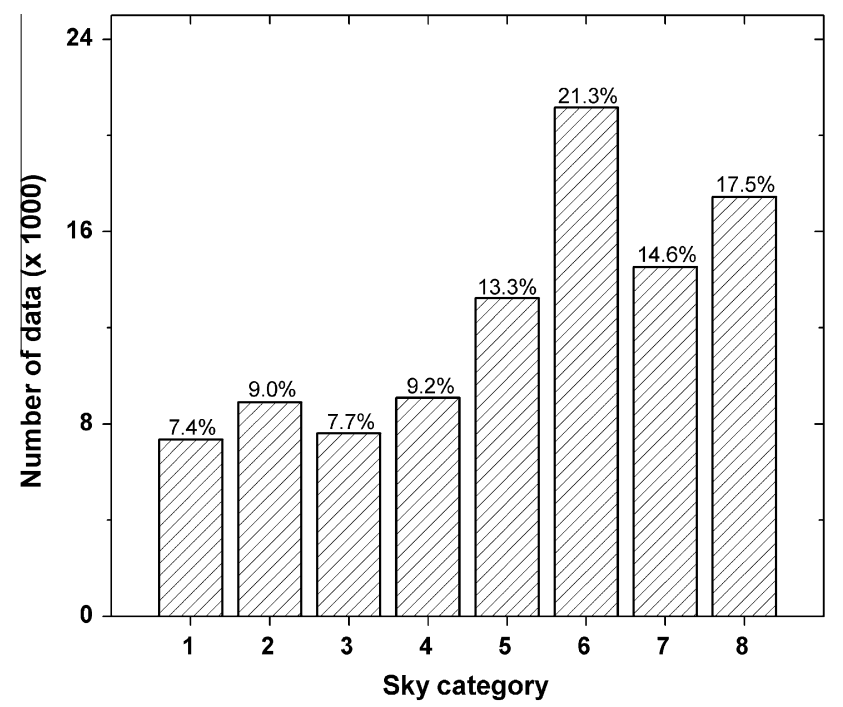

Fig. 4. Number of data into each sky category at Madrid for the period 1980-2005.

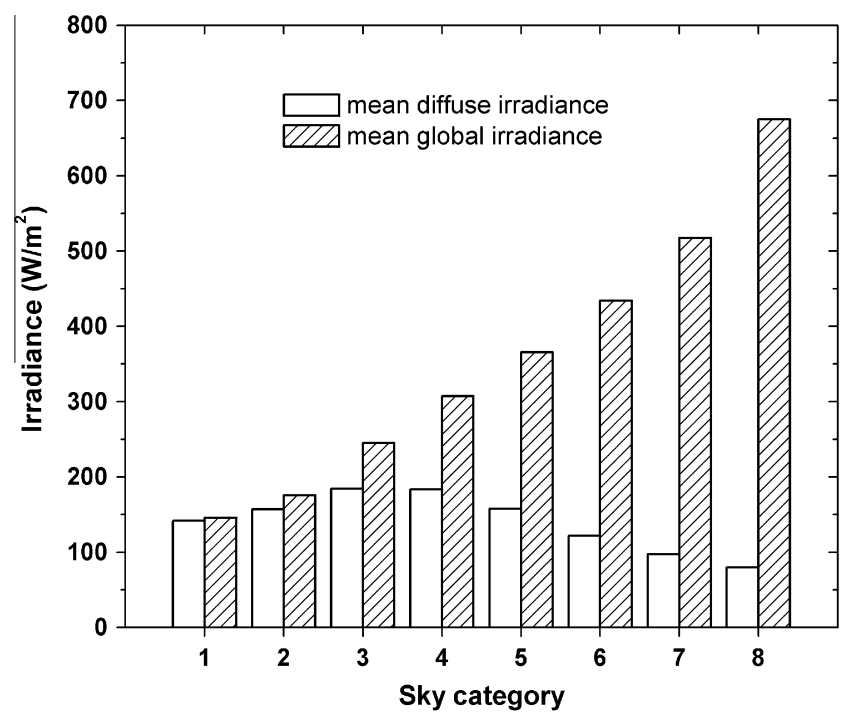

Fig. 5. Mean global and diffuse irradiance for each sky category for the period 1980-2005 at Madrid.

est values correspond to clear skies. The range of variation is between 13.46 klux and 22.82 klux.

\section{Estimation of diffuse illuminance on vertical surface}

The estimation of vertical illuminances from irradiances is carried out throughout an empirical model. In this case, the calculation process takes several steps. Firstly, vertical irradiance is calculated from the horizontal one and then, vertical illuminance is calculated from vertical irradiance.

\subsection{Estimation of diffuse irradiance on vertical surface}

To calculate vertical irradiance from the horizontal one, the Perez model was used. Three types of models were developed by Perez et al. to calculate: (a) global, diffuse and direct horizontal luminous efficacy, (b) diffuse irradiance and illuminance on tilted surfaces and (c) sky luminance. The model used here corresponds to the second type and is described in Perez et al. [31]. A simplified ver-

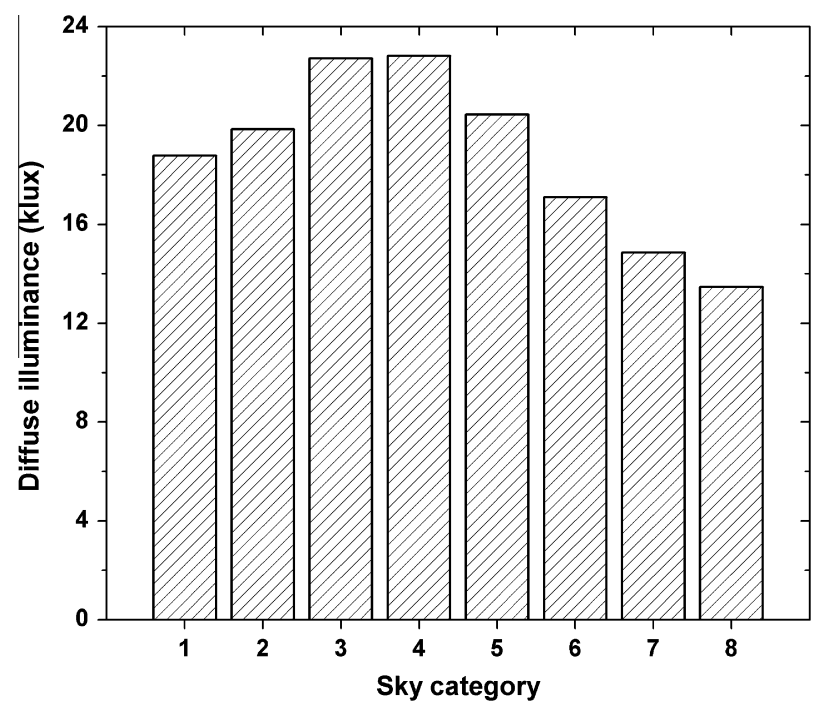

Fig. 6. As in Fig. 5 but for mean diffuse illuminance.

sion of the model is given in Perez et al. [32]. This model has been validated by numerous authors (Robledo and Soler [6], De Rosa et al. [18], Chirarattananon et al. [7], Joshi et al. [22], Janjai et al. [8]). The expression of the simplified Perez model is given as:

$E_{d T L T}=E_{d h}\left[\left(1-F_{1}\right) \cos ^{2} \frac{T L T}{2}+F_{1} \frac{a_{0}}{a_{1}}+F_{2} \operatorname{senTLT}\right]$

$E_{d T L T}$ is diffuse irradiance on a surface tilted an angle TLT (TLT $=90^{\circ}$ for a vertical surface), $E_{d h}$ is diffuse irradiance on horizontal surface, $F_{1}$ and $F_{2}$ are the circumsolar and horizon brightness coefficients, respectively, given by:

$$
\begin{aligned}
& F_{1}=\max \left[\left\{0,\left\{F_{11}+F_{12} \Delta+F_{13}\left(\frac{\pi}{180}\right) Z\right\}\right\}\right] \\
& F_{2}=F_{21}+F_{22} \Delta+F_{23}\left(\frac{\pi}{180}\right) Z
\end{aligned}
$$

where $Z$ is the zenith angle, $\Delta$, the brightness index and $F_{i j}$, coefficients established for each sky clearness index $\varepsilon$ category [14]; coefficients $a_{0}$ and $a_{1}$ are given as:

$a_{0}=\max [0, \cos$ INC $], a_{1}=\max \left[\cos 85^{\circ}, \cos Z\right]$

where INC is the incident angle on the tilted surface and $Z$ is the zenith angle.

Several studies have found that the accuracy of the Perez model increases when local coefficients are used (Robledo and Soler [33,34], Chirarattananon et al. [7] and De Rosa et al. [18]). Robledo and Soler [33] determined the empirical $F_{i j}$ coefficients for Madrid based on measurements of irradiance carried out at ETSAM (Madrid) for the period 1992-1994. These values are reproduced in Table 1 and have been used in this work.

Table 1

\begin{tabular}{|c|c|c|c|c|c|c|c|}
\hline $\begin{array}{l}\varepsilon \\
\text { bin }\end{array}$ & $\begin{array}{l}\text { Upper } \\
\text { limit }\end{array}$ & $F_{11}$ & $F_{12}$ & $F_{13}$ & $F_{21}$ & $F_{22}$ & $F_{23}$ \\
\hline 1 & 1.065 & -0.114 & 0.562 & 0.052 & -0.041 & 0.081 & -0.012 \\
\hline 2 & 1.230 & 0.213 & 0.318 & -0.123 & 0.110 & -0.350 & -0.003 \\
\hline 3 & 1.500 & 0.617 & -0.608 & -0.151 & 0.191 & -0.611 & 0.045 \\
\hline 4 & 1.950 & 0.670 & -0.225 & -0.294 & 0.149 & -0.231 & -0.001 \\
\hline 5 & 2.800 & 0.995 & -1.123 & -0.386 & 0.377 & -0.959 & -0.014 \\
\hline 6 & 4.500 & 0.873 & 0.143 & -0.568 & 0.425 & -1.298 & 0.040 \\
\hline 7 & 6.200 & 0.673 & 0.183 & -0.491 & 0.290 & -1.450 & 0.167 \\
\hline 8 & - & -0.065 & 5.540 & -0.430 & 0.276 & -0.799 & 0.044 \\
\hline
\end{tabular}

Irradiance coefficients determined for Madrid for all the vertical planes. (source: [33]) 
Coefficients in Table 1 are valid for all vertical planes with any orientation. Values from this Table are used in expression (8) to calculate $F_{1}$ and $F_{2}$; then, the diffuse vertical irradiance is calculated by expression (6). Formulae to calculate solar geometry magnitudes have been taken from Iqbal [35]. Four representative vertical orientations, North, South, East and West were considered and the diffuse irradiance reaching these types of surfaces was estimated.

\subsection{Estimation of diffuse illuminance from irradiance}

In this step, estimated diffuse irradiance on vertical surface $E_{d v}$ ( TLT $=90^{\circ}$ ) is used to determine diffuse illuminance $L_{d v}$ through:

$L_{d v}=K_{d v} E_{d v}$

where $K_{d v}$ is the luminous efficacy on a vertical surface. In order to estimate $K_{d v}$, the model of Robledo and Soler [6] has been used. These authors proposed a model with local empirical coefficients calculated for Madrid. Following their work, a different relationship is used for each orientation. The empirical expressions for North, South, East and West orientations are given by:
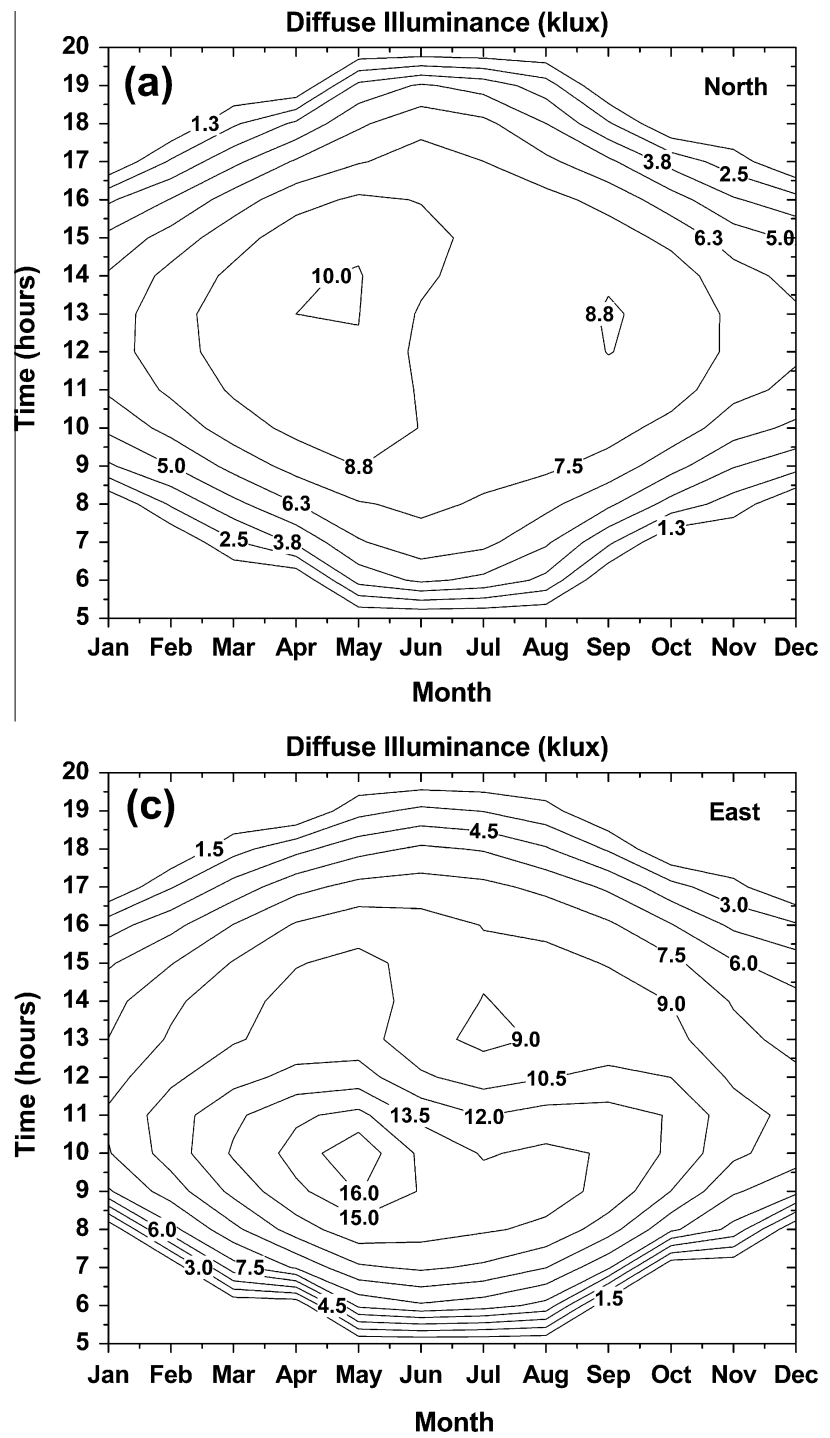

$$
\begin{aligned}
& K_{d v \text { North }}=96.04(\sin \alpha)^{-0.08} \Delta^{-0.039} \\
& K_{d v \text { South }}=108.0(\sin \alpha)^{-0.088} \Delta^{-0.171} \\
& K_{d v \text { East }}=112.2(\sin \alpha)^{-0.061} \Delta^{-0.009} \\
& K_{d v \text { West }}=112.63(\sin \alpha)^{-0.0406} \Delta^{-0.027}
\end{aligned}
$$

where $\alpha$ is the solar altitude and $\Delta$, the brightness index. In order to determine $K_{d v}$ for intermediate orientations, the same authors recommend an interpolation of the values given by these expressions.

Following the steps above, hourly values of vertical illuminance were obtained. Results are based on the hourly measurements of horizontal irradiance of AEMET for the period 1980-2005.

In Fig. 7, monthly mean hourly values of diffuse illuminance are shown for North, South, East and West orientations by means of iso-lux diagrams. Maximum daily values for North and South orientations are reached at noon and show a variation range along the year of about 10-6 klux and 21-14 klux, respectively; These daily maximum values have a variation about 17-9 klux in the case of orientations East and West, being these values reached in the morning and in the afternoon, respectively. Cumulative frequency distributions for diffuse illuminance for the four orientations on a monthly and annual basis were determined and shown in
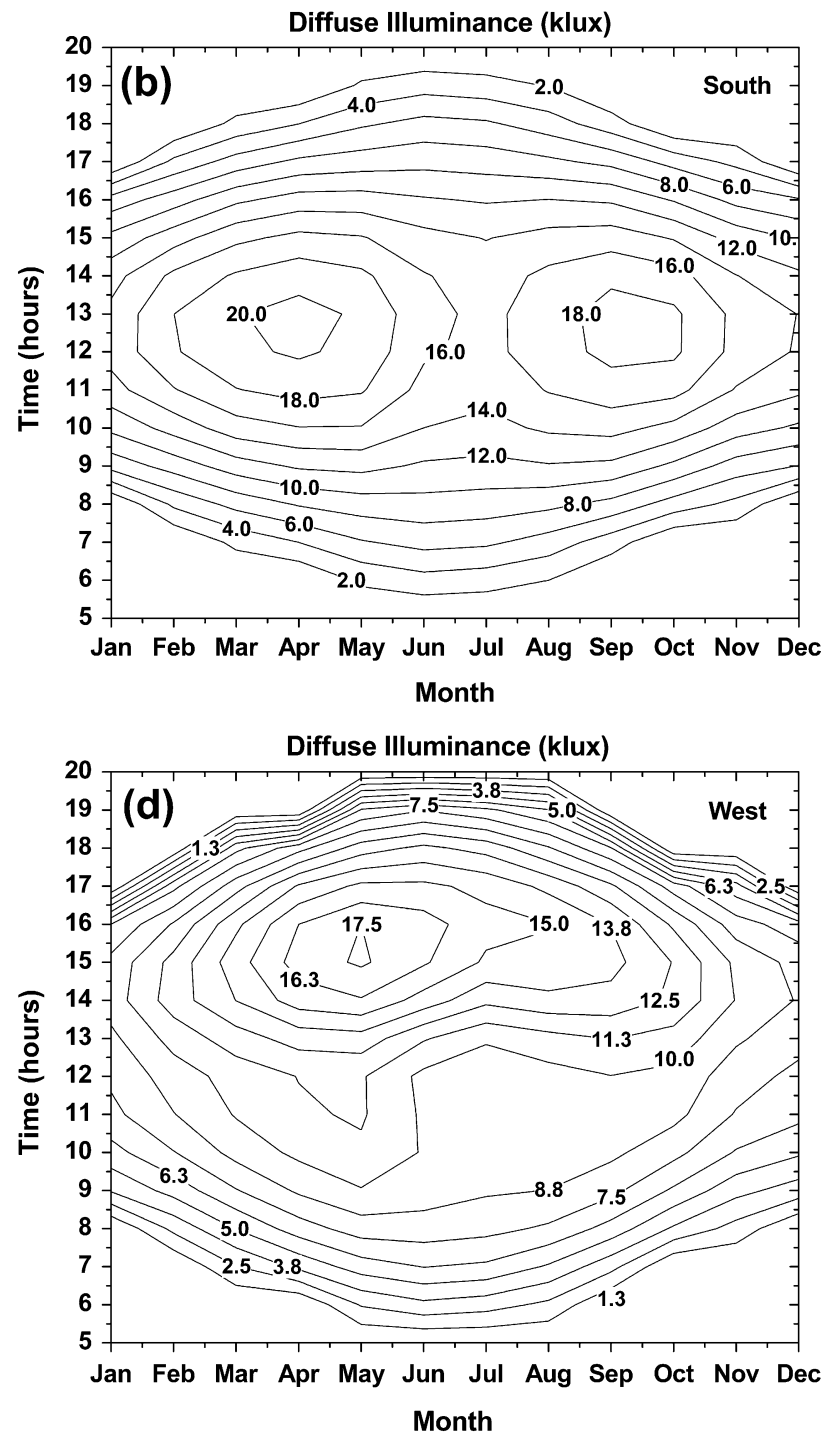

Fig. 7. Iso-lux lines diagram of diffuse illuminance on vertical surface for Madrid for the period 1980-2005. 

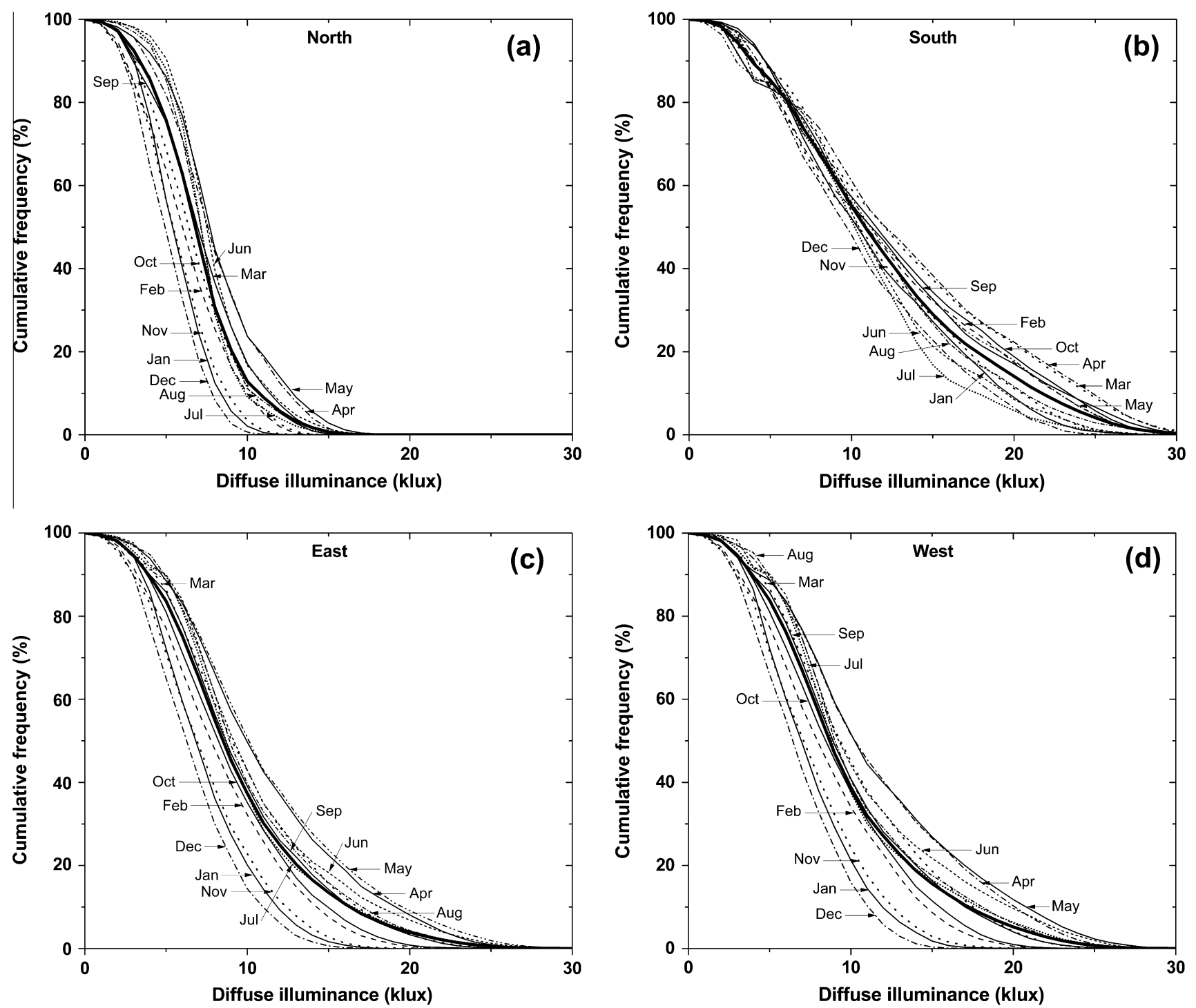

Fig. 8. Cumulative frequency distribution for diffuse illuminance on vertical surface for Madrid for the period 1980-2005 on a monthly basis.

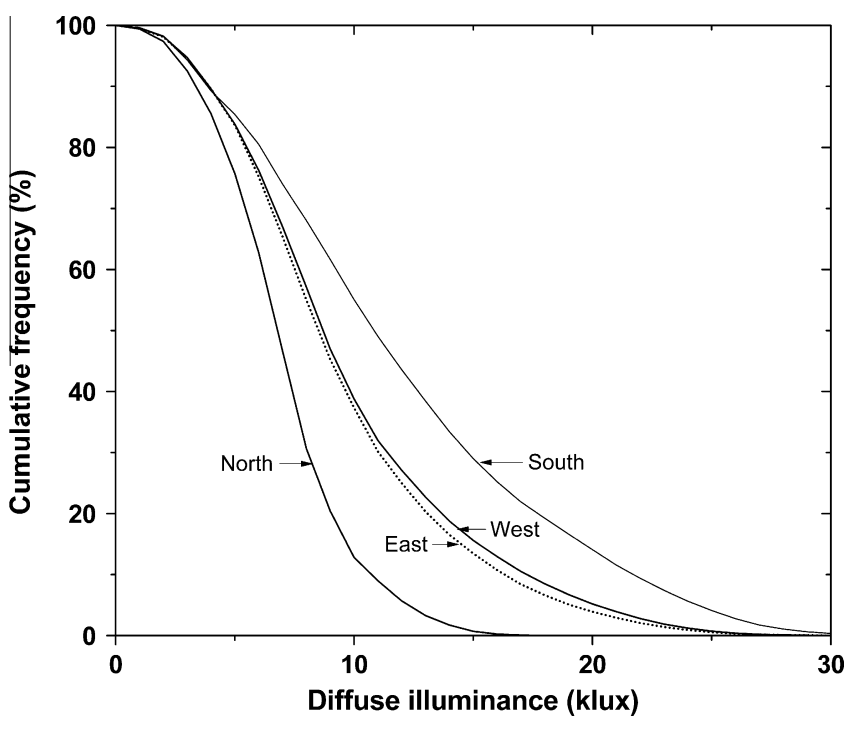

Fig. 9. Cumulative frequency distribution for diffuse illuminance on vertical surface for Madrid for the period 1980-2005.
Fig. 8a-d. Darker line calculated by considering the whole data set represents an average behavior for all months. By considering all orientations, no daylight availability is found above 30 klux. From these graphs, information about months presenting higher daylight availability for each orientation can be obtained.

For a better understanding, lines calculated from the whole data set have been put together in Fig. 9. From this Figure, it is possible to appreciate differences for the four surfaces. For illuminace values less than 4 klux, no difference is found among different orientations. By increasing illuminance values, differences among orientations increase. As an example, for the case of the North orientation, a $20 \%$ of illuminance data exceed a value of 9 klux while, for the same percentage, a value of $18 \mathrm{klux}$ is obtained for the South orientation and a value of 14 klux for East and West orientations.

\section{Conclusions}

Natural light determines and configures spaces where people carry out daily activities. So, nowadays, the architectural design is strongly influenced by daylighting techniques. In order for natural illumination to be implemented in architectural projects, it is 
necessary to know daylight availability. According to this, the main aim of this work has been to provide actual data of solar illuminance representing the climatic behavior of this energy resource in a specific geographical area. Monthly mean hourly values of diffuse illuminance were provided for horizontal and vertical surfaces oriented to the four cardinal points. The results were based on experimental data taken at Madrid $\left(40^{\circ} 27^{\prime} \mathrm{N}, 3^{\circ} 43^{\prime} \mathrm{W}\right)$, Spain, in a period of 26 years (1980-2005) and on models that have been extensively validated in scientific literature. This work was intended to be a continuation of the studies carried out by Robledo and Soler during the past years. Due to the use of long-term series, results of the data analysis carried out in this paper provide a reliable data base for diffuse illuminace availability that can be useful to technicians dealing with illumination of indoor spaces in order to obtain a better visual comfort and significant electric energy savings.

\section{Acknowledgement}

Data provided by National Meteorological Agency of Spain (AEMET) is gratefully acknowledged.

\section{References}

[1] Markou MT, Bartzokas A, Kambezidis HD. Daylight climatology in Athens, Greece. types of diurnal variation of illuminance levels. Int J Climatol 2009;29(14):2137-45.

[2] López G, Gueymard CA. Clear-sky solar luminous efficacy determination using artificial neural networks. Sol Energy 2007;81:929-39.

[3] Pérez-Burgos A, Bilbao J, De Miguel A. An evaluation of illuminance measurements at Valladolid (Spain). J Atmos Sol Terr Phys 2007;69(8):939-46.

[4] Oteiza P, Soler A. Eficacia luminosa de la radiación solar global, difusa y directa para cielos despejados en superficies horizontales, Libro de Actas del VII Congreso Ibérico de Energía Solar. Sol Energy Soc 1994;23:189-94.

[5] Robledo L, Soler A. On the luminous efficacy of diffuse solar radiation, 2001. Energy Convers Manage 2001;42(10):1181-90.

[6] Robledo L, Soler A. Modeling the luminous efficacy of diffuse solar radiation on inclined surfaces for all sky conditions. Energy Convers Manage 2003;44(1): 177-89.

[7] Chirarattananon S, Rukkwansuk P, Chaiwiwatworakul P, Pakdeepol P. Evaluation of vertical illuminance and irradiance models against data from north Bangkok. Build Environ 2007;42(11):3894-904.

[8] Janjai S, Wattan R, Nunez M. A statistical approach for estimating diffuse illuminance on vertical surfaces. Build Environ 2009;44(10):2097-105.

[9] Fakra AH, Boyer H, Miranville F, Bigot D. A simple evaluation of global and diffuse luminous efficacy for all sky conditions in tropical and humid climate. Renew Energy 2011;36(1):298-306.

[10] Cucumo MA, De Rosa A, Ferraro V, Kaliakatsos D, Marinelli V. Predicting diffuse illuminance on vertical surfaces at Arcavacata di Rende (Italy) for various types of sky. Build Environ 2008;43(10):1678-86.

[11] Robledo L, Soler A. Luminous efficacy of global solar radiation for clear skies. Energy Convers Manage 2000;41(16):1769-79.

[12] Olseth JA, Skartveit A. Observed and modelled hourly luminous efficacies under arbitrary cloudiness. Sol Energy 1989;42(3):221-33.

[13] Muneer T, Gul MS, Kinghorn D. Development of a meteorological illuminance model for daylight computations. Appl Energy 1998;59(4):235-60.
[14] Perez R, Ineichen P, Seals R, Michalsky J, Stewart R. Modeling daylight availability and irradiance components from direct and global irradiance. Sol Energy 1990;44(5):271-89.

[15] Vartianen E. A comparison of luminous efficacy models with illuminance and irradiance measurements. Renew Energy 2000;20:265-77.

[16] Muneer T, Gul MS, Kubie J. Models for estimating solar radiation and illuminance from meteorological parameters. J Sol Energy Eng 2000;122(3):146-53.

[17] De Rosa A, Ferraro V, Kaliakatsos D, Marinelli V. Simplified correlations of global, direct and diffuse luminous efficacy on horizontal and vertical surfaces. Energy Build 2008;40(11):1991-2001.

[18] De Rosa A, Ferraro V, Kaliakatsos D, Marinelli V. Calculating diffuse illuminance on vertical surfaces in different sky conditions. Energy 2008;33(11):1703-10.

[19] Ruiz E, Soler A, Robledo L. Assessment of Muneer's luminous efficacy models in Madrid and a proposal for new models based on his approach. J Sol Energy Eng 2001;123(3):220-4.

[20] Cucumo M, De Rosa A, Ferraro V, Kaliakatsos D, Marinelli V. Experimental data of global and diffuse luminous efficacy on vertical surface at Arcavacata di Rende and comparisons with calculation models. Energy Convers Manage 2009;50(1):166-73.

[21] Muneer T. Solar radiation and daylight models. 2nd ed. Oxford, Burlington, MA: Elsevier Butterworth-Heinemann; 2004

[22] Joshi M, Sawhney RL, Buddhi D. Estimation of luminous efficacy of daylight and exterior illuminance for composite climate of Indore city in Mid Western India. Renew Energy 2007;32(8):1363-78.

[23] Markou MT, Kambezidis HD, Bartzokas A, Darula S, Kittler R. Generation of daylight reference years for two European cities with different climate: Athens, Greece and Bratislava. Slovakia, Atmos Res. 2007;86:315-29.

[24] Ne'eman E, Lyubensky V, Setter I, Manes A, Lanetz A. Daylight availability database for Israel and the nearby region, Solar light advancements in the dawn of the 21st century. In: Solaris 2005 2nd Joint Conference, Hellenic Illumination Committee, Athenas, Greece, p. 76-83.

[25] Bartzokas A, Darula S, Kambezidis HD, Kittler R. Sky luminance distribution in central Europe and the Mediterranean area during the winter period. J Atmos Sol Terr Phys 2003;65:113-9.

[26] Bartzokas A, Kambezidis HD, Darula S, Kittler R. Comparison between winter and summer sky-luminance distribution in Central Europe and in the Eastern Mediterranean. J Atmos Solar Terr Phys 2005;67:709-18.

[27] Pérez-Burgos A, De Miguel A, Bilbao J. Daylight illuminance on horizontal and vertical surfaces for clear skies. Case study of shaded surfaces. Sol Energy 2010;84(1):137-43.

[28] Soler A, Gopinathan K, Robledo L, Ruiz E. Month-hour distributions of zenith luminance and diffuse illuminance in Madrid. Energy Convers Manage 2004;45:1141-52.

[29] Kambezidis H, Oikonomou Th, Zevgolis D. Daylight climatology in the Athens urban environment: guidance for building designers. Lighting Res Technol 2002;34(4):297-312.

[30] Chirarattananon S, Chaiwiwatworakul P, Pattanasethanon S. Daylight availability and models for global and diffuse horizontal illuminance and irradiance for Bangkok. Renew Energy 2002;26(1):69-89.

[31] Perez R, Stewart R, Arbogast C, Seals R, Scott J. An anisotropic hourly diffuse radiation model for sloping surfaces, Description performance validation, site dependency evaluation. Sol Energy 1986;36(6):481-98.

[32] Perez R, Seals R, Ineichen R, Stewart R, Menicucci D. A new simplified version of the Perez diffuse irradiance model for tilted surfaces. Sol Energy 1987;39(3):221-31.

[33] Robledo L, Soler A. Modeling irradiance on inclined planes with an anisotropic model. Energy 1998;23(3):193-201.

[34] Robledo L, Soler A. Dependence on surface orientation of coefficients in the circumsolar simplified Perez illuminance model for vertical planes at madrid. Energy Convers Manage 1998;39(15):1585-95.

[35] Iqbal M. An introduction to solar radiation. Toronto, Canada: Academic Press; 1983. 